DOI: 10.12731/wsd-2017-4-2-41-58

УДК 616.12 - 008 (-17)

\title{
АНАЛИЗ ЧАСТОТЫ И СТРУКТУРЫ ЗАБОЛЕВАНИЙ СЕРДЕЧНО-СОСУДИСТОЙ СИСТЕМЫ У МИГРАНТОВ КРАЙНЕГО СЕВЕРА В ПЕРИОД РЕАДАПТАЦИИ К НОВЫМ КЛИМАТИЧЕСКИМ УСЛОВИЯМ
}

\section{Яскевич Р.А., Москаленко О.Л.}

Цель. Изучение частоты и структуры заболеваний сердечно-сосудистой системь у мигрантов Крайнего Севера в период реадаптации к новым климатическим условиям.

Материалы и методы. Обследовано 145 мигрантов Крайнего Севера с артериальной гипертонией (АГ) II-II стадии, прибывших на постоянное место жительства в южные регионы Центральной Сибири. Обследование включало анкетирование, клинические, инструментальные, функииональные и лабораторные методы исследования.

Результаты. После переезда в иентральную Сибирь у мигрантов Крайнего Севера кризовое течение АГ встречается чаще у лии с длительностью проживания на Крайнем Севере 30 и более лет. Увеличение частоты кризов отмечено у мужчин, в отличие от женщин. Частота развития инсульта после миграции у женщин увеличивается, но не меняется у мужчин. После переезда у мигрантов выявлено увеличение частоты встречаемости заболеваний, осложняющих течение гипертонии. Увеличение частоты встречаемости приступов стенокардии и инсультов и тенденция к увеличению частоты случаев инфаркта миокарда и сердечной недостаточности после переезда в центральную Сибирь, вызвано повымением уровня невротических расстройств, связанных с сочиальными и экономическими факторами.

Заключение. Выявленные в результате проведенного исследования закономерности иелесообразно учитывать при построении программ профилактики и реабилитации у мигрантов Крайнего Севера, с обязательной оценкой уровня адаптивных и реадаптивных возможностей организма. План последующего наблюдения и объем необходимых мероприятий должен составляться индивидуально с учетом выявленных сердечно-сосудистых заболеваний, сопутствующей патологии и факторов 
риска. При наличии сердечно-сосудистых заболеваний мигрантам необходимо обращаться к врачу кардиологу с иелью коррекичи медикаментозной и немедикаментозной терапии при реадаптации.

Ключевые слова: сердечно-сосудистая система; артериальная гипертония; Крайний Север; реадаптация.

\section{ANALYSIS OF THE INCIDENCE AND STRUCTURE OF THE CARDIOVASCULAR SYSTEM DISEASES IN THE FAR NORTH MIGRANTS OVER THE PERIOD OF READAPTATION TO THE NEW CLIMATIC CONDITIONS}

\section{Yaskevich R.A., Moskalenko O.L.}

The purpose of the study. To study the frequency and structure of cardiovascular diseases of the Far North migrants within the period of readaptation to the new climatic conditions.

Materials and methods. 145 migrants with stages II-III of arterial hypertension (AH) coming from the Far North arrived in the southern regions of central Siberia for permanent residence. The survey included questionnaires, clinical, instrumental, and functional and laboratory research methods.

Results. After moving to central Siberia, the hypertensive crisis is more common in people who lived in the Far North for 30 years or more. An increase in the hypertensive crisis frequency was observed in men, rather than women, whereas the stroke incidence in female migrants gets higher, but remains unchanged in male migrants. An increase in the incidence of diseases that complicate the hypertension progression was detected in the migrants during the period following the migration. An increase in the incidence of angina attacks and strokes as well as a trend towards an increase in the incidence of myocardial infarction and heart failure after moving to central Siberia is caused by an increase in the level of neurotic disorders associated with social and economic factors.

Conclusion. The identified patterns should be taken into account in the construction of prevention and rehabilitation programs for the Far North migrants along with an obligatory assessment of the adaptive and readaptive capabilities of the organism. Both the follow-up plan and the list of the required measures should be made individually, while taking into account the 
identified cardiovascular diseases, concomitant pathology and risk factors. Should the migrant be diagnosed with any cardiovascular diseases, they need to consult a cardiologist with the purpose of correcting both medicated and medication-free therapy for the readaptation period.

Keywords: cardiovascular system; arterial hypertension; Far North; readaptation.

Введение: Ежегодно из регионов Крайнего Севера в более комфортные климатогеографические зоны России выезжает большое количество людей. Одним из основных факторов, связанных с миграционными процессами, является изменение в состоянии здоровья, особенно со стороны сердечно-сосудистой системы [7, с. 12-15; 8, с. 129; 11, с. 123]. В суровых климатических условиях сердечно-сосудистая система (как высокореактивная), одна из первых включается в приспособительные реакции [8, с. 129]. Данная причина, безусловно, сказывается на производительности труда и трудоспособности. В регионах с экстремальными климатическими условиями это может служить причиной отрицательного миграционного потока и дестабилизацией населения, в частности в регионах Крайнего Севера.

На долю сердечно-сосудистых заболеваний (СС3) в мире приходится $48 \%$ случаев смерти [2, с. 123-125], в РФ по данным оперативного учета за январь-декабрь 2016 года - 47,4\% соответственно [19, с. 717-718]. Особую важность приобретает изучение различий в заболеваемости сердечно-сосудистыми заболеваниями у жителей различных регионов страны и в том числе среди населения Крайнего Севера и Сибири [3, с. 23-29; 9 , с. $55-57 ; 10$, с. $92-95 ; 13$, с. $73-76 ; 16$, с. $61-69 ; 20$, с. $109-110 ; 24$, c. 138], так как артериальная гипертония (АГ) и ишемическая болезнь сердца (ИБС) занимают ведущее место в структуре причин обратной миграции лиц из районов Крайнего Севера [7, с. 12-15; 11, с. 123; 12, с. 172].

Деятельность человека в условиях Крайнего Севера протекает на пределе его физиологических возможностей, при почти полной мобилизации функциональных резервов [8, с. 129]. Устойчивая адаптация связана с постоянным напряжением управляющих механизмов, перестройкой нервных и гуморальных соотношений, которые постепенно истощаются $[17$, c. $43-51]$. При очень сильном или длительном воздействии, либо при слабости адаптационных механизмов организма, возникает дезадаптация (нарушение или срыв адаптации) и развиваются патологические состояния $[14$, с. $361-367 ; 15$, с. $76-83]$. 
По своим психофизиологическим механизмам этап реадаптации имеет много общего с этапом адаптации, и чем больше срок пребывания в измененных условиях, тем труднее и дольше происходит реадаптация к обычным условиям жизни [7, с. 12-15; 11, с. 123; 18, с. 1275-1280].

Следует отметить, что несмотря на то, что вопросам реадаптации жителей Крайнего Севера, с переездом на новое место жительства в другие климатические условия посвящено крайне небольшое число работ $[1$, с. $88-90 ; 4$, с. $261-272 ; 5$, с. $311-326 ; 6$, с. $64-67 ; 21$, с. $247-255 ; 22$, c. $10-34 ; 23$, с. $672-677 ; 26$, с. 157-162], важность изучаемой проблемы и необходимость решения вопроса выбора регионов, куда целесообразен переезд жителей Севера, с меньшей «платой за реадаптацию» остается актуальной.

Цель исследования: Изучить частоту и структуру заболеваний сердечно-сосудистой системы у мигрантов крайнего севера в период реадаптации к новым климатическим условиям.

Материалы и методы: В исследование было включено 199 пациентов с артериальной гипертонией (АГ) II-III стадии (по рекомендациям ВНОК-2010, ESH/ESC-2009), средний возраст 66,02 лет (95\%ДИ: 64,867,2). Обследуемые были распределены на основную и контрольную группы. Основную группу составили мигранты Крайнего Севера (145 чел., средний возраст - 67,8 лет (95\%ДИ: 66,8-68,8)), проживающие ранее на Крайнем Севере и переехавшие в дальнейшем на постоянное место жительства в Центральную Сибирь (г. Красноярск и г. Минусинск). В качестве группы контроля были обследованы 54 пациента с АГ, проживающие в г. Красноярске (средний возраст - 63,7士 1,4 лет (95\%ДИ: 67,2$71,4))$. Группы по возрасту не отличались $(\mathrm{p}=0,19)$. Пациенты основной и контрольной групп были разделены по полу, времени пребывания на Крайнем Севере и времени проживания по возвращению в Южные регионы Центральной Сибири (реадаптация).

Обследование включало: общеклинические методы, анкетирование, эхокардиография, электрокардиография покоя, суточное мониторирование артериального давления, изменение скорости распространения пульсовой волны по артериям мышечного и эластического типов, суточное мониторирование ЭКГ по Холтеру, антропометрию, исследование липидов сыворотки, проведение стандартного теста толерантности к глюкозе.

Исследование соответствовало этическим стандартам, разработанным в соответствии с Хельсинкской декларацией Всемирной ассоциации «Этические принципы проведения научных медицинских исследований 
с участием человека» (2000 г.) и с Правилами клинической практики в Российской Федерации, утвержденными Приказом Минздрава РФ №266 (2003 г.) и проводилось в соответствии с информированным согласием на участие.

Статистическая обработка результатов исследования осуществлялась с помощью пакета программ Statistica 6.1. Полученные данные представлены в виде средней величины и доверительного интервала. Две независимые группы сравнивались с помощью U-критерия Манна-Уитни, Анализ различия частот в двух независимых группах проводился при помощи точного критерия Фишера с двусторонней доверительной вероятностью, критерия $\chi^{2}$ с поправкой Йетса. Статистически значимыми считали различия при $\mathrm{p}<0,05$.

Результаты и обсуждение: По данным проведенного исследования при анализе структуры АГ среди мигрантов, прибывших на новое место жительства установлено, что АГ 1 степени встречалась у $33,8 \%$ обследованных, а АГ 2 и АГЗ степени у 52,4\% и 16,6\% соответственно. АГ риск 2 отмечалась у $30,6 \%$, АГ риск 3 у $32,6 \%$ и АГ риск 4 у $36,7 \%$ соответственно (рис. 1). Среди мужчин АГ риск 2 отмечался у $12,5 \%$, риск $3-25 \%$ и риск 4 у 62,5\%. У женщин эти показатели были следующими: $34,1 \%$, $34,1 \%, 31,7 \%$ соответственно.
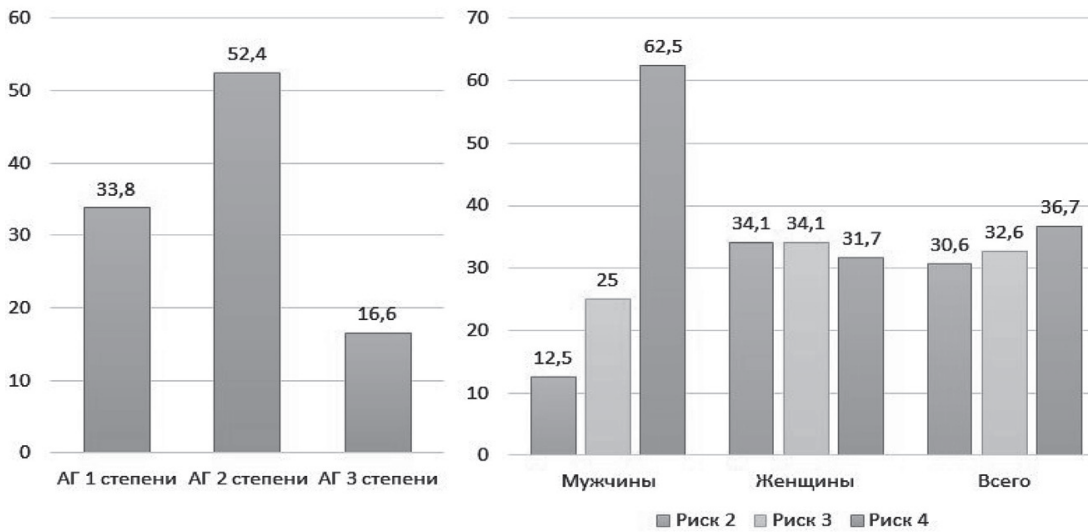

Рис. 1. Структура артериальной гипертонии среди обследованных мигрантов Крайнего Севера

Проведен анализ уровней АД у мигрантов Крайнего Севера с АГ в зависимости от сроков проживания на Крайнем Севере. С этой целью об- 
следуемые мигранты были разделены на 3 группы (1 группа от 10 до 19 лет, вторая группа 20-29 лет, третья группа более 30 лет). Отмечалось увеличение уровней САД и ДАД в зависимости от времени проживания в условиях Крайнего Севера (табл. 1). Выявлены статистически значимые различия по уровням САД среди обследованных проживших на Крайнем Севере до 20 лет и лицами, прожившими более 30 лет ( $\mathrm{p}=0,001)$. Различия между остальными группами по уровням САД имели лишь тенденции. По уровням ДАД также отмечалось увеличение показателей в зависимости от сроков проживания. Статистически значимые различия по уровням ДАД выявлены среди лиц, проживших на Крайнем Севере менее 20 лет и прожившими более 30 лет ( $\mathrm{p}=0,013)$, а также с прожившими 20-29 лет $(\mathrm{p}=0,05)$ соответственно.

Таблица 1.

Уровни артериального давления у мигрантов в зависимости от сроков проживания на Крайнем Севере

\begin{tabular}{|c|c|c|c|c|}
\hline & \multicolumn{3}{|c|}{ Сроки проживания на Крайнем Севере } & \multirow[b]{2}{*}{$p$} \\
\hline & 10-19 лет & 20-29 лет & $\geq 30$ лет & \\
\hline $\begin{array}{c}\text { САД } \\
\text { (мм рт. ст.) }\end{array}$ & $\begin{array}{c}129,0 \\
{[121,27-136,73]}\end{array}$ & $\begin{array}{c}139,81 \\
{[134,21-145,41]}\end{array}$ & $\begin{array}{c}143,21 \\
{[139,19-147,23]}\end{array}$ & $\begin{array}{l}\mathbf{p}_{1-2=} \mathbf{0 , 0 1 3} \\
\mathbf{p}_{1-3=}=\mathbf{0 , 0 0 1} \\
p_{2-3}=0,389\end{array}$ \\
\hline $\begin{array}{c}\text { ДАД } \\
\text { (мм рт. ст.) }\end{array}$ & $\begin{array}{c}79,32 \\
{[74,53-84,10]}\end{array}$ & $\begin{array}{c}85,37 \\
{[82,71-88,04]}\end{array}$ & $\begin{array}{c}86,98 \\
{[84,58-89,37]}\end{array}$ & $\begin{array}{l}\mathbf{p}_{1-2=} \mathbf{0 , 0 5 0} \\
\mathbf{p}_{1-3} \mathbf{0 , 0 1 3} \\
\mathrm{p}_{23}=0,580\end{array}$ \\
\hline $\begin{array}{c}\text { ПАД } \\
\text { (мм рт. ст.) }\end{array}$ & $\begin{array}{c}49,68 \\
{[43,04-56,33]}\end{array}$ & $\begin{array}{c}54,44 \\
{[50,52-58,36]}\end{array}$ & $\begin{array}{c}56,23 \\
{[53,33-59,14]}\end{array}$ & $\begin{array}{l}p_{1-2-2}=0,061 \\
\mathbf{p}_{1-3=}=0,020 \\
p_{2-3=}=0,451\end{array}$ \\
\hline
\end{tabular}

Проанализированы показатели АД у мигрантов Крайнего Севера в зависимости от сроков реадаптации к новым климатическим условиям. Для этого обследуемые мигранты были разделены на группы в зависимости от сроков проживания при возвращении в южные регионы Центральной Сибири. Первую группу составили обследуемые с длительностью проживания до 5 лет, вторую 6-10 лет, третью более 10 лет соответственно. Выявлена линейная зависимость повышения уровней САД от сроков проживания в новых климатических условиях (табл.2), при этом уровни САД у мигрантов через 10 после переезда были выше ( $\mathrm{p}=0,02)$, по сравнению с лицами, прожившими в новых климатических условиях менее 3 лет. По уровням ДАД прожившие до 3 лет и свыше 10 не различались, в то время 
как у проживших в новых климатических условиях от 3 до 10 лет уровни ДАД были несколько выше, на уровне тенденций.

Таблийа 2.

Уровни артериального давления у мигрантов в зависимости от сроков реадаптации

\begin{tabular}{|c|c|c|c|c|}
\hline & \multicolumn{3}{|c|}{ Сроки реадаптации } & \multirow{2}{*}{$p$} \\
\hline & до 3 лет & от 3 до10 лет & $\geq 10$ лет & \\
\hline $\begin{array}{c}\text { САД } \\
\text { (мм рт. ст.) }\end{array}$ & $\begin{array}{c}132,62 \\
{[126,65-138,59]}\end{array}$ & $\begin{array}{c}140,73 \\
{[135,69-145,78]}\end{array}$ & $\begin{array}{c}142,45 \\
{[137,60-147,31]}\end{array}$ & $\begin{array}{l}\mathbf{p}_{1-2=} \mathbf{0 , 0 5 0} \\
\mathbf{p}_{1-3=} \mathbf{0 , 0 1 9} \\
\mathrm{p}_{2-3=} 0,597\end{array}$ \\
\hline $\begin{array}{c}\text { ДАД } \\
\text { (мм рт. ст.) }\end{array}$ & $\begin{array}{c}85,24 \\
{[81,22-89,26]}\end{array}$ & $\begin{array}{c}86,04 \\
{[82,94-89,14]}\end{array}$ & $\begin{array}{c}85,17 \\
{[82,59-87,76]}\end{array}$ & $\begin{array}{l}\mathrm{p}_{1-2=} 0,957 \\
\mathrm{p}_{1-3=} 0,884 \\
\mathrm{p}_{2-3=} 0,910\end{array}$ \\
\hline $\begin{array}{c}\text { ПАД } \\
\text { (мм рт. ст.) }\end{array}$ & $\begin{array}{c}47,37 \\
{[42,63-52,13]}\end{array}$ & $\begin{array}{c}54,69 \\
{[51,41-57,99]}\end{array}$ & $\begin{array}{c}57,27 \\
{[53,70-60,85]}\end{array}$ & $\begin{array}{l}\mathbf{p}_{1-2=} \mathbf{0 , 0 1 9} \\
\mathbf{p}_{1-3=} \mathbf{0 , 0 0 1} \\
\mathrm{p}_{2-3=} 0,365\end{array}$ \\
\hline
\end{tabular}

В условиях Крайнего Севера в зависимости от воздействия на организм внешних факторов и устойчивости функциональных систем, а также реактивности организма и длительности проживания в данном регионе гипертоническая болезнь приобретает свою качественную характеристику, в связи с чем индивидуальные особенности организма и различные ответные реакции на воздействие экстремальных факторов обусловливают различное течение гипертонической болезни [7, с. 12-15; 8, с. 129]. Изменение качественной характеристики гипертонической болезни проявляется, как правило, после 10 лет проживания в условиях высоких широт. У этих больных отмечается высокий уровень невротизма и чаще проявляется кризовое течение заболевания, переходящее в неблагоприятный клинический исход [7, с. 12-15]. По-видимому, у больных гипертонической болезнью с неблагоприятным течением отмечаются изменения реактивности в высших вегетативных центрах, которые обусловливают повышенную чувствительность больных к изменениям внешней среды Крайнего Севера [8, с. 129]. В суровых климатических условиях функциональные системы у больных находятся в состоянии напряжения.

Изучена частота встречаемости гипертонических кризов у мигрантов Крайнего Севера с артериальной гипертонией в период проживания на Крайнем Севере и после переезда в центральную Сибирь. При переезде в центральную Сибирь у мигрантов Крайнего Севера с артериальной гипертонией как у мужчин, так и среди женщин отмечается увеличение количества гипертонических кризов (рис. 2). 
Однако имелись половые различия в частоте встречаемости гипертонических кризов у мигрантов Крайнего Севера с АГ в период проживания на Крайнем Севере и после переезда в центральную Сибирь. Среди женщин количество гипертонических кризов было выше по сравнению с мужчинами, как до, так и после переезда в новые климатические условия.

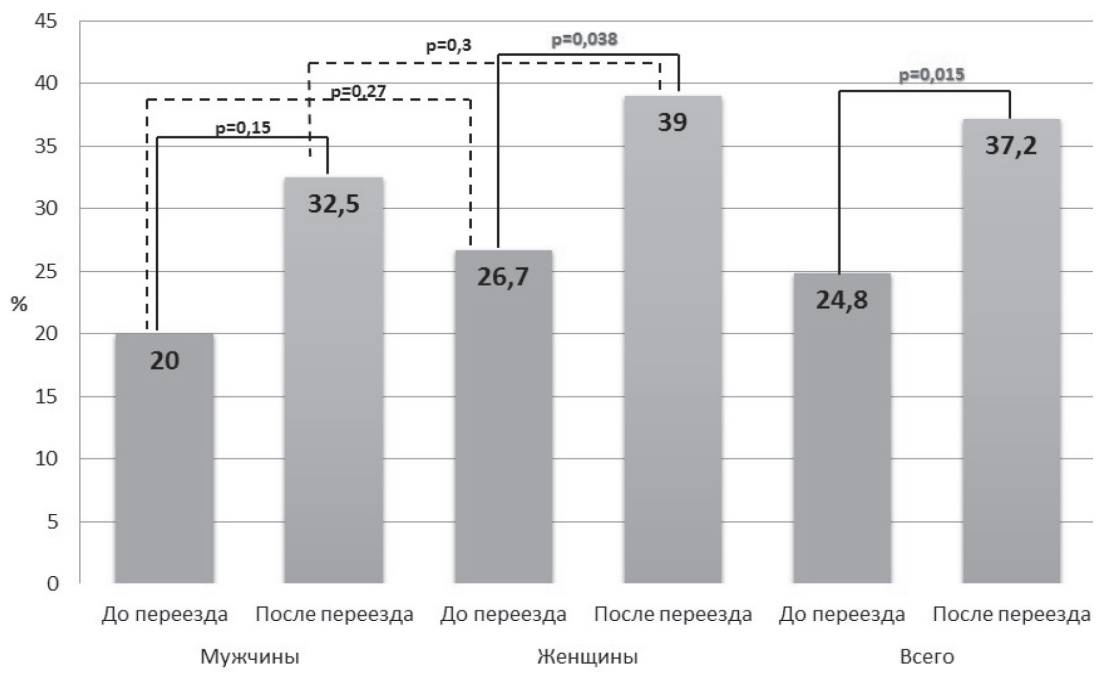

Рис. 2. Частота встречаемости гипертонических кризов у мигрантов Крайнего Севера до и после переезда в центральную Сибирь

В ходе исследования была установлена тенденция к снижению частоты гипертонических кризов у мужчин в зависимости от увеличения сроков реадаптации. У женщин была выявлена тенденция к снижению частоты гипертонических кризов со сроком реадаптации от 3 -х до 10 лет, однако у женщин со сроком реадаптации более 10 лет, напротив отмечается тенденция к увеличению частоты гипертонических кризов. В целом у мужчин и у женщин после переезда в центральную Сибирь отмечается тенденция к увеличению частоты гипертонических кризов в зависимости от увеличения сроков реадаптации. Однако в группе больных со сроком реадаптации менее 10 лет отмечается тенденция к снижению частоты гипертонических кризов (рис. 3).

После переезда в новые климатические условия у мигрантов Крайнего Севера с АГ отмечается увеличение частоты встречаемости заболеваний, осложняющих течение гипертонии. Так АГ в сочетании с ПИКС встре- 
чалась у $5,5 \%$, из них у женщин $2,9 \%$ и мужчин $12,5 \%$. ИБС у мигрантов Крайнего Севера после переезда на новое место жительства наблюдалась в форме стенокардии в $22,8 \%$ случаев, из них у женщин $24,8 \%$ и мужчин $17,5 \%$ соответственно, осложнения в виде ИМ встречались 9,7\% случаев, из них у женщин 9,5\% и мужчин $10 \%$ (табл. 3). Частота встречаемости инсульта составила 10,3\%, из них у женщин 11,3\% и мужчин 7,5\%. Сердечная недостаточность была выявлена у $6,9 \%$ обследуемых, из них у женщин 4,8\% и мужчин $12,5 \%$ соответственно.

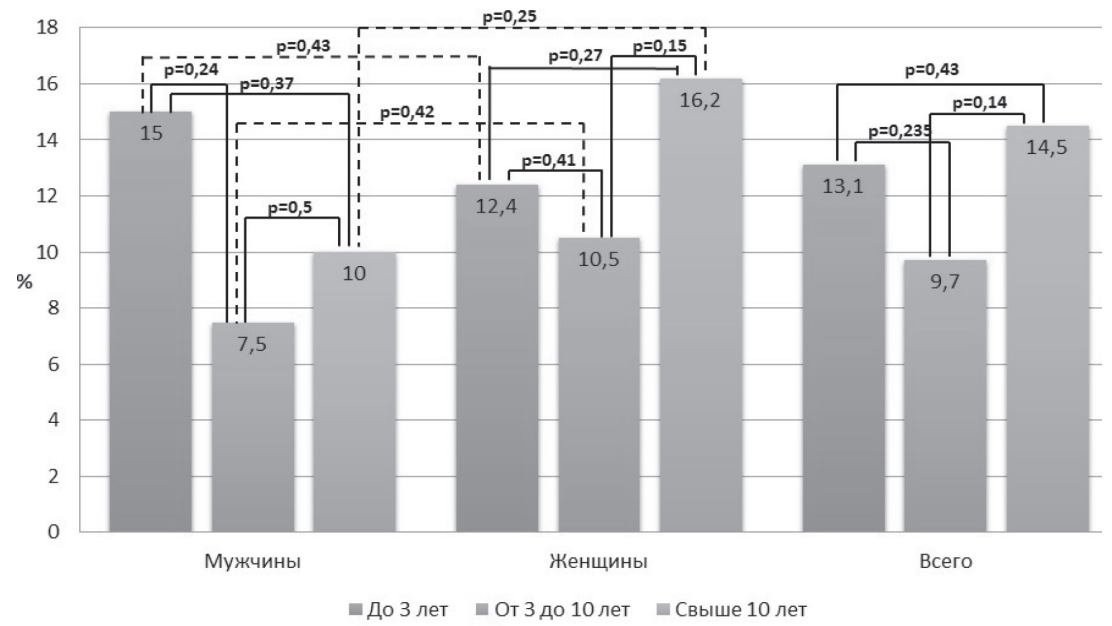

Рис. 3. Частота встречаемости гипертонических кризов у мигрантов Крайнего Севера в зависимости от сроков реадаптации.

При анализе частоты встречаемости заболеваний, осложняющих течение артериальной гипертонии у мигрантов Крайнего Севера, до и после переезда в новые климатические условия отмечается статистически значимое в увеличении частоты приступов стенокардии и инсультов и тенденция к увеличению частоты случаев инфаркта миокарда и сердечной недостаточности после переезда в центральную Сибирь (табл. 3).

У мужчин мигрантов Крайнего Севера выявлена тенденция к увеличению частоты инсультов и сердечной недостаточности и снижение частоты приступов стенокардии и инфаркта миокарда после переезда в центральную Сибирь (табл. 3), в то время как среди женщин мигрантов Крайнего Севера выявлено статистически значимое увеличении частоты встречаемости стенокардии, инфаркта миокарда и инсульта после переез- 
да в центральную Сибирь. Также отмечена тенденция в увеличении случаев сердечной недостаточности после переезда (табл. 3).

Таблица 3.

Частота встречаемости заболеваний, осложняющих течение артериальной гипертонии у мигрантов до и после переезда

\begin{tabular}{|l|c|c|c|c|c|c|c|c|c|}
\hline & \multicolumn{3}{|c|}{ МУЖЧИНЫ } & \multicolumn{3}{c|}{ ЖЕНЩИНЫ } & \multicolumn{3}{c|}{ ВСЕГО } \\
\cline { 2 - 11 } & до & после & $\boldsymbol{p}$ & до & после & $\boldsymbol{p}$ & до & после & $\boldsymbol{p}$ \\
\hline Стенокардия & $22,5 \%$ & $17,5 \%$ & 0,39 & $7,6 \%$ & $24,8 \%$ & $\mathbf{0 , 0 0 0 6}$ & $11,7 \%$ & $22,8 \%$ & $\mathbf{0 , 0 0 9}$ \\
\hline $\begin{array}{l}\text { Инфаркт } \\
\text { миокарда }\end{array}$ & $12,5 \%$ & $10 \%$ & 0,5 & $2,9 \%$ & $9,5 \%$ & $\mathbf{0 , 0 4}$ & $5,5 \%$ & $9,7 \%$ & $\mathbf{0 , 1 3}$ \\
\hline Инсульт & $5 \%$ & $7,5 \%$ & 0,5 & $2,9 \%$ & $11,4 \%$ & $\mathbf{0 , 0 1 4}$ & $3,4 \%$ & $10,3 \%$ & $\mathbf{0 , 0 1 7}$ \\
\hline $\begin{array}{l}\text { Сердечная } \\
\text { недостаточ- } \\
\text { ность }\end{array}$ & $7,5 \%$ & $12,5 \%$ & 0,36 & $2,9 \%$ & $4,8 \%$ & 0,36 & $4,1 \%$ & $6,9 \%$ & $\mathbf{0 , 2 2}$ \\
\hline
\end{tabular}

При сравнении частоты встречаемости заболеваний, осложняющих течение артериальной гипертонии у мигрантов Крайнего Севера между мужчинами и женщинами, отмечалась более низкая частота встречаемости стенокардии $(\mathrm{p}=0,016)$ и ИМ $(\mathrm{p}=0,03)$ до переезда в новые климатические условия у женщин в сравнении с мужчинами и частоты встречаемости инсультов и сердечной недостаточности на уровне тенденций соответственно. После переезда отмечались тенденции к большей частоте встречаемости стенокардии и инсульта и меньшей частоте встречаемости инфарктов миокарда и сердечной недостаточности в сравнении с мужчинами.

Причиной возникновения гипертонических кризов, учащения приступов стенокардии у мигрантов может быть повышенный уровень невротизации, связанный с социально-экономическими факторами (смена работы, снижение уровня материального дохода, уход на пенсию, смена психологического климата в семье) [7, с. 12-15; 11, с. 123]. У некоторых больных за счет перестройки морфо-функциональных структур с истощением различных функциональных систем организма реадаптация заканчивалась летальным исходом, особенно у лиц в возрасте старше 50 лет [25, с. 337-339].

Заключение: Резюмируя вышеизложенное, следует отметить, что после переезда в центральную Сибирь у мигрантов Крайнего Севера кризовое течение АГ встречается чаще у лиц с длительностью проживания на Крайнем Севере 30 и более лет. Увеличение частоты кризов отмечено у мужчин, в отличие от женщин, у которых выявлено уменьшение частоты кризов. Частота 
развития инсульта после миграции у женщин увеличивается, но не меняется у мужчин. После переезда в новые климатические условия у мигрантов Крайнего Севера с АГ отмечается увеличение частоты встречаемости заболеваний, осложняющих течение гипертонии. Отмечается статистически значимое увеличение частоты встречаемости приступов стенокардии и инсультов и тенденция к увеличению частоты случаев инфаркта миокарда и сердечной недостаточности после переезда в центральную Сибирь.

Реадаптация мигрантов Крайнего Севера хуже проходит в возрасте старше 50 лет. Эта группа лиц, при переезде в новые климато-географические условия, требует пристального внимания врачей, особенно при наличии ИБС. В этом возрасте ИБС, как правило, сочетается с наличием АГ, поэтому данная группа больных должна регулярно принимать лечение с адекватно подобранной терапией.

Мигрантам, прибывшим из Крайнего Севера, по приезду в новые климато-географические условия, необходимо рекомендовать проведение обследования с целью выявления факторов риска, изучения компонентного состава массы тела, изучения имеющихся тенденций питания, своевременного выявления метаболического синдрома. План последующего наблюдения и объем необходимых мероприятий должен составляться индивидуально с учетом выявленных сердечно-сосудистых заболеваний, сопутствующей патологии и факторов риска. При наличии сердечно-сосудистых заболеваний необходимо обращаться к врачу кардиологу с целью коррекции медикаментозной и немедикаментозной терапии при реадаптации.

Выявленные в результате проведенного исследования закономерности целесообразно учитывать при построении программ профилактики и реабилитации у данного контингента больных, с обязательной оценкой уровня адаптивных и реадаптивных возможностей организма, так как неадекватная адаптация и реадаптация играет решающую роль в возникновении основных неинфекционных заболеваний, профилактика которых составляет главную нерешенную проблему современной медицины. Следовательно, оценивая уровень адаптивных и реадаптивных возможностей организма, можно решить одну из важнейших проблем диагностики здоровья в целом.

\section{Список литературы}

1. Благинин А.А., Саввин Ю.Ю., Пятибрат Е.Д., Уховский Д.М. Особенности реадаптации военнослужащих из районов Крайнего Севера к климатогеографическим условиям средних широт // Вестн. Росс. воен.-мед. акад. 2013. № 2. С. 88-90. 
2. Всемирный атлас профилактики сердечно-сосудистых заболеваний и борьбы с ними. Под ред.: Mendis S., Puska P., Norrving В. ВОЗ. Женева. 2013. $155 \mathrm{c}$.

3. Гапон Л.И., Шуркевич Н., Ветошкин А.С. Структурно- функциональные изменения сердца и суточный профиль артериального давления у больных артериальной гипертонией на Крайнем Севере // Клиническая медицина. 2009. № 9. С. 23-29.

4. Игнатова И.А., Зайцева О.И., Покидышева Л.И. и др. Взаимосвязь патологии слуха с эмоциональным состоянием мигрантов Севера // В мире научных открытий. 2012. № 2.4. С. 261-272.

5. Игнатова И.А., Яскевич Р.А., Деревянных Е.В., Балашова Н.А. Характер влияния нейросенсорной тугоухости на качество жизни у пожилых мигрантов Крайнего Севера с артериальной гипертонией // Медико-социальная помощь для ветеранов: качество и перспективы: матер. Всероссийск. науч.-практ. конф. с междунар. участ., посвящ. 70-летию КГБУЗ «Красноярский краевой госпиталь для ветеранов войн». Красноярск, 2016. С. 311-326.

6. Петрова И.А., Эверт Л.С., Зайцева О.И., Платонова Н.В. Адаптация детей-северян к новым климатогеографическим условиям проживания в центральных регионах Сибири // Якутский медицинский журнал. 2013. № 2(42). C. 64-67.

7. Поликарпов Л. С., Хамнагадаев И.И., Яскевич Р. А., Деревянных Е.В. Артериальная гипертония (распространенность, профилактика, адаптация и реадаптация к различным экологическим условиям). Красноярск: Изд-во КрасГМУ, 2010. 289 с.

8. Поликарпов Л.С., Лапко А.В., Хамнагадаев И.И., Яскевич Р.А. Метеотропные реакции сердечно-сосудистой системы и их профилактика. Новосибирск: Наука, 2005. 196 с.

9. Поликарпов Л.С., Хамнагадаев И.И., Иванова Е.Б. и др. Частота сердечно-сосудистой патологии, содержание микроэлементов в различных средах в условиях Севера // Сибирский медицинский журнал (г. Томск). 2005. T. 20. № 2. C. 55-57.

10. Поликарпов Л.С., Хамнагадаев И.И., Манчук В.Т. и др. Социально-эпидемиологическая характеристика артериальной гипертонии в условиях Севера и Сибири // Сибирское медицинское обозрение. 2008. № 4 (52). С. 92-95.

11. Поликарпов Л.С., Хамнагадаев И.И., Яскевич Р.А. и др. Ишемическая болезнь сердца (распространенность, профилактика, адаптация и реадаптация в различных экологических условиях). Красноярск: Изд-во КрасГМУ, 2011. $328 \mathrm{c}$. 
12. Поликарпов Л.С., Яскевич Р.А., Деревянных Е.В. и др. Ишемическая болезнь сердца, особенности клинического течения в условиях Крайнего Севера. Красноярск: Изд-во КрасГМУ, 2011. 334 с.

13. Попова Е.К., Архипова Н.С., Томский М.И. Частота артериальной гипертензии в группе больных ишемической болезнью сердца пожилого возраста, проживающих в условиях Крайнего Севера // Сибирский медицинский журнал (Иркутск). 2015. Т. 132. № 1. С. 73-76.

14. Пуликов А.С., Москаленко О.Л., Зайцева О.И. Адаптационный потенциал юношей Красноярского края как показатель состояния здоровья // В мире научных открытий. 2011. Т. 16. № 4. С. 361-367.

15. Пуликов А.С., Москаленко О.Л., Зайцева О.И. Особенности адаптации организма юношей в возрастном аспекте в различных экологических условиях // В мире научных открытий. 2011. № 5. С. 76-83.

16. Татаринова О.В. Сердечно-сосудистая патология и ее факторы риска в якутской популяции // Атеросклероз. 2014. Т. 10. № 2. С. 61-69.

17. Хаснулин П.В., Воевода М.И., Хаснулин П.В., Артамонова О.Г. Современный взгляд на проблему артериальной гипертензии в приполярных и арктических регионах. Обзор литературы // Экология человека. 2016. №3. С. 43-51.

18. Шилов С.Н., Игнатова И.А., Муллер Т.А. и др. Теория адаптации-реадаптации в современных представлениях «здоровье» // Фундаментальные исследования. 2015. № 1-6. С. 1275-1280.

19. Щербакова Е.М. Россия: предварительные демографические итоги 2016 года (часть II) //Демоскоп Weekly. 2017. № 717-718.

20. Эверт Л.С. Артериальная гипертония у детей в различных климато-географических регионах Сибири // Сибирское медицинское обозрение. 2008. Т. 54, № 6. С. 109-110.

21. Яскевич Р.А. Показатели тревоги и депрессии в различные периоды реадаптации к новым климатическим условиям у мигрантов Крайнего Севера с артериальной гипертонией // Психологическое здоровье человека: жизненный ресурс и жизненный потенциал: матер. Международной науч.-практ. конф. 2016. С. 247-255.

22. Яскевич Р.А., Москаленко О.Л. Антропометрические особенности и компонентный состав массы тела у мужчин мигрантов Крайнего Севера с артериальной гипертонией // В мире научных открытий. 2016. № 10 (82). С. 10-34.

23. Яскевич Р.А., Хамнагадаев И.И., Деревянных Е.В. и др. Тревожно-депрессивные расстройства у пожилых мигрантов Крайнего Севера в период реадаптации к новым климатическим условиям // Успехи геронтологии. 2014. T. 27. № 4. C. $672-677$. 
24. Artyukhov I.P., Grinshtein Y.I., Petrova M.M. et al. Prevalence of arterial hypertension in the Krasnoyarsk Krai (Siberia, Russia). BMC Cardiovascular Disorders. 2017. 17(1):138. doi: 10.1186/s12872-017-0559-5.

25. Polikarpov L.S., Yaskevich R.A., Derevyannich E.V. et al. Readaptation of patients with arterial hypertension long-term residents of the Far North to new climatic conditions. International Journal of Circumpolar Health. 2012. V. 72. № S1, pp. 337-339.

26. Yaskevich R.A., Khamnagadaev I.I., Dereviannikh Ye.V. et al. Anxiety depressive disorders in elderly migrants of the far North in the period of readaptation to new climatic conditions. Advances in Gerontology. 2015. V. 5. № 3, pp. 157-162.

\section{References}

1. Blaginin A.A., Savvin Yu.Yu., Pyatibrat E.D., Ukhovskiy D.M. Osobennosti readaptatsii voennosluzhashchikh iz rayonov Kraynego Severa k klimatogeograficheskim usloviyam srednikh shirot [Features of the readaptation of servicemen from the regions of the Far North to the climatogeographic conditions of the middle latitudes]. Vestn. Ross. voen.-med. akad. [Bulletin of the Russian Military Medical Academy]. 2013. № 2, pp. 88-90.

2. Vsemirnyy atlas profilaktiki serdechno-sosudistykh zabolevaniy i bor'by s nimi [World Atlas of Prevention and Control of Cardiovascular Diseases]. ed.: Mendis S., Puska P., Norrving B. VOZ. Zheneva. 2013. 155 p.

3. Gapon L.I., Shurkevich N., Vetoshkin A.S. Strukturno-funtsional'nye izmeneniya serdtsa i sutochnyy profil' arterial'nogo davleniya u bol'nykh arterial'noy gipertoniey na Kraynem Severe [Structural-functional changes in the heart and daily profile of arterial pressure in patients with arterial hypertension in the Far North]. Klinicheskaya meditsina [Clinical medicine]. 2009. № 9, pp. 23-29.

4. Ignatova I.A., Zaytseva O.I., Pokidysheva L.I. i dr. Vzaimosvyaz' patologii slukha s emotsional'nym sostoyaniem migrantov Severa [Interrelation of the pathology of hearing with the emotional state of migrants of the North]. V mire nauchnykh otkrytiy [Siberian Journal of Life Sciences and Agriculture]. 2012. № 2.4, pp. 261-272.

5. Ignatova I.A., Yaskevich R.A., Derevyannykh E.V., Balashova N.A. Kharakter vliyaniya neyrosensornoy tugoukhosti na kachestvo zhizni u pozhilykh migrantov Kraynego Severa s arterial'noy gipertoniey [Character of the influence of neurosensory hearing loss on the quality of life in elderly migrants of the Far North with arterial hypertension]. Mediko-sotsial'naya pomoshch' dlya veteranov: kachestvo i perspektivy [Medico-social assistance for veterans: quality and prospects: mater. All-Russian. Scientific-practical. Conf. With in- 
tern. Participant]: mater. Vserossiysk. nauch.-prakt. konf. s mezhdunar. uchast., posvyashch. 70-letiyu KGBUZ «Krasnoyarskiy kraevoy gospital' dlya veteranov voyn». Krasnoyarsk. 2016, pp. 311-326.

6. Petrova I.A., Evert L.S., Zaytseva O.I., Platonova N.V. Adaptatsiya detey-severyan k novym klimatogeograficheskim usloviyam prozhivaniya v tsentral'nykh regionakh Sibiri [Adaptation of children-northerners to new climatogeographic conditions of residence in the central regions of Siberia]. Yakutskiy meditsinskiy zhurnal [Yakutsk Medical Journal]. 2013. № 2(42), pp. 64-67.

7. Polikarpov L. S., Khamnagadaev I.I., Yaskevich R. A., Derevyannykh E.V. Arterial'naya gipertoniya (rasprostranennost', profilaktika, adaptatsiya i readaptatsiya $k$ razlichnym ekologicheskim usloviyam) [Arterial hypertension (prevalence, prevention, adaptation and adaptation to various environmental conditions)]. Krasnoyarsk: Izd-vo KrasGMU. 2010. 289 p.

8. Polikarpov L.S., Lapko A.V., Khamnagadaev I.I., Yaskevich R.A. Meteotropnye reaktsii serdechno-sosudistoy sistemy i ikh profilaktika [Meteotropic reactions of the cardiovascular system and their prevention]. Novosibirsk: Nauka. 2005. $196 \mathrm{p}$.

9. Polikarpov L.S., Khamnagadaev I.I., Ivanova E.B. i dr. Chastota serdechno-sosudistoy patologii, soderzhanie mikroelementov v razlichnykh sredakh v usloviyakh Severa [The frequency of cardiovascular pathology, the content of trace elements in various environments in the North]. Sibirskiy meditsinskiy zhurnal (Tomsk) [Siberian Medical Journal (Tomsk)]. 2005. V. 20. № 2, pp. 55-57.

10. Polikarpov L.S., Khamnagadaev I.I., Manchuk V.T. et al. Sotsial'no-epidemiologicheskaya kharakteristika arterial'noy gipertonii v usloviyakh Severa i Sibiri [Socio-epidemiological characteristics of arterial hypertension in the conditions of the North and Siberia]. Sibirskoe meditsinskoe obozrenie [Siberian Medical Review]. 2008. № 4 (52), pp. 92-95.

11. Polikarpov L.S., Khamnagadaev I.I., Yaskevich R.A. et al. Ishemicheskaya bolezn'serdtsa (rasprostranennost', profilaktika, adaptatsiya i readaptatsiya $v$ razlichnykh ekologicheskikh usloviyakh) [Coronary heart disease (prevalence, prevention, adaptation and re-adaptation in various environmental conditions)]. Krasnoyarsk: Izd-vo KrasGMU. 2011. 328 p.

12. Polikarpov L.S., Yaskevich R.A., Derevyannykh E.V. i dr. Ishemicheskaya bolezn' serdtsa, osobennosti klinicheskogo techeniya $v$ usloviyakh Kraynego Severa [Ischemic heart disease, features of the clinical course in the Far North]. Krasnoyarsk: Izd-vo KrasGMU. 2011. 334 p.

13. Popova E.K., Arkhipova N.S., Tomskiy M.I. Chastota arterial'noy gipertenzii v gruppe bol'nykh ishemicheskoy bolezn'yu serdtsa pozhilogo vozrasta, prozhi- 
vayushchikh v usloviyakh Kraynego Severa [The frequency of arterial hypertension in the group of patients with ischemic heart disease of elderly people living in the Far North conditions]. Sibirskiy meditsinskiy zhurnal (Irkutsk) [Siberian Medical Journal (Irkutsk)]. 2015. V. 132. № 1, pp. 73-76.

14. Pulikov A.S., Moskalenko O.L., Zaytseva O.I. Adaptatsionnyy potentsial yunoshey Krasnoyarskogo kraya kak pokazatel' sostoyaniya zdorov'ya [Adaptation Potential of the Young Men of the Krasnoyarsk Territory as an Indicator of Health Status]. V mire nauchnykh otkrytiy [Siberian Journal of Life Sciences and Agriculture]. 2011. V. 16. № 4, pp. 361-367.

15. Pulikov A.S., Moskalenko O.L., Zaytseva O.I. Osobennosti adaptatsii organizma yunoshey v vozrastnom aspekte $\mathrm{v}$ razlichnykh ekologicheskikh usloviyakh [Peculiarities of the adaptation of the organism of young men in the age aspect in different ecological conditions]. V mire nauchnykh otkrytiy [Siberian Journal of Life Sciences and Agriculture]. 2011. № 5, pp. 76-83.

16. Tatarinova O.V. Serdechno-sosudistaya patologiya i ee faktory riska v yakutskoy populyatsii [Cardiovascular pathology and its risk factors in the Yakut population]. Ateroskleroz [Atherosclerosis]. 2014. T. 10. № 2. S. 61-69.

17. Khasnulin P.V., Voevoda M.I., Khasnulin P.V., Artamonova O.G. Sovremennyy vzglyad na problemu arterial'noy gipertenzii v pripolyarnykh i arkticheskikh regionakh. Obzor literatury [Modern view on the problem of arterial hypertension in the circumpolar and arctic regions. A review of the literature]. Ekologiya cheloveka [Human ecology]. 2016. №3, pp. 43-51.

18. Shilov S.N., Ignatova I.A., Muller T.A. et al. Teoriya adaptatsii-readaptatsii v sovremennykh predstavleniyakh «zdorov'e» [Theory of adaptation-readaptation in modern concepts of "health"]. Fundamental'nye issledovaniya [Fundamental research]. 2015. № 1-6, pp. 1275-1280.

19. Shcherbakova E.M. Rossiya: predvaritel'nye demograficheskie itogi 2016 goda (chast' II) [Russia: preliminary demographic results of 2016 (Part II)]. Demoskop Weekly [Demoscope Weekly]. 2017. № 717-718.

20. Evert L.S. Arterial'naya gipertoniya u detey v razlichnykh klimato-geograficheskikh regionakh Sibiri [Arterial hypertension in children in different climatic and geographical regions of Siberia]. Sibirskoe meditsinskoe obozrenie [Siberian Medical Review]. 2008. V. 54. № 6, pp. 109-110.

21. Yaskevich R.A. Pokazateli trevogi i depressii v razlichnye periody readaptatsii k novym klimaticheskim usloviyam u migrantov Kraynego Severa c arterial'noy gipertoniey [Indicators of anxiety and depression in different periods of adaptation to new climatic conditions in migrants of the Far North with arterial hypertension]. Psikhologicheskoe zdorov'e cheloveka: zhiznennyy resurs $i$ 
zhiznennyy potentsial [Psychological health of man: life resource and life potential]. 2016, pp. 247-255.

22. Yaskevich R.A., Moskalenko O.L. Antropometricheskie osobennosti i komponentnyy sostav massy tela u muzhchin migrantov Kraynego Severa s arterial'noy gipertoniey [Anthropometric features and component composition of body weight in men of migrants of the Far North with arterial hypertension]. $V$ mire nauchnykh otkrytiy [Siberian Journal of Life Sciences and Agriculture]. 2016. № 10 (82), pp. 10-34.

23. Yaskevich R.A., Khamnagadaev I.I., Derevyannykh E.V. i dr. Trevozhno-depressivnye rasstroystva u pozhilykh migrantov Kraynego Severa v period readaptatsii k novym klimaticheskim usloviyam [Anxiety-depressive disorders in elderly migrants of the Far North in the period of readaptation to new climatic conditions]. Uspekhi gerontologii [Successes of gerontology]. 2014. V. 27. № 4, pp. 672-677.

24. Artyukhov I.P., Grinshtein Y.I., Petrova M.M. et al. Prevalence of arterial hypertension in the Krasnoyarsk Krai (Siberia, Russia). BMC Cardiovascular Disorders. 2017. 17(1):138. doi: 10.1186/s12872-017-0559-5.

25. Polikarpov L.S., Yaskevich R.A., Derevyannich E. V. et al. Readaptation of patients with arterial hypertension long-term residents of the Far North to new climatic conditions. International Journal of Circumpolar Health. 2012. T. 72. № S1. S. 337-339.

26. Yaskevich R.A., Khamnagadaev I.I., Dereviannikh Ye.V. et al. Anxiety depressive disorders in elderly migrants of the far North in the period of readaptation to new climatic conditions. Advances in Gerontology. 2015. T. 5. № 3. S. 157-162.

\section{ДАННЫЕ ОБ АВТОРАХ}

Яскевич Роман Анатольевич, доцент кафедры пропедевтики внутренних болезней и терапии, ведущий научный сотрудник группы патологии сердечно-сосудистой системы, кандидат медицинских наук, доцент

Федеральное государственное бюджетное научное учреждение «Научно-исследовательский институт медицинских проблем Севера»; ГБОУ ВПО «КрасГМУ им. проф. Ф.В. Войно-Ясенецкого» MЗ $P \Phi$

ул. Партизана Железняка, 32, г. Красноярск, 660022, Российская Федерация; ул. Партизана Железняка, 1а, г. Красноярск, 660022, Российская Федерация cardio@impn.ru 
Москаленко Ольга Леонидовна, старший научный сотрудник, кандидат биологических наук

Федеральное государственное бюджетное научное учреэндение «Научно-исследовательский институт медицинских проблем Севера»

ул. Партизана Железняка, 32, г. Красноярск, 660022, Российская Федераичия

gre-ll@mail.ru

\section{DATA ABOUT THE AUTHORS}

Yaskevich Roman Anatolyevich, Associate Professor at Department of Propedeutics of Internal Diseases and Therapy, Leading Researcher of the Group Pathology of the Cardiovascular System, Candidate of Medical Science, Docent

Scientific Research Institute of medical problems of the North; Krasnoyarsk State Medical University named after Professor V.F. Voino-Yasenetzkiy

1a, P. Zheleznyaka Str., Krasnoyarsk, 660022, Russian Federation; $3 g$, P. Zheleznyaka Str., Krasnoyarsk, 660022, Russian Federation cardio@impn.ru

Moskalenko Olga Leonidovna, Senior Researcher, Candidate of Biological Sciences

Scientific Research Institute of medical problems of the North 3g, P. Zheleznyaka Str., Krasnoyarsk, 660022, Russian Federation gre-ll@mail.ru 